\title{
Five Year Retrospective Study of Profile of Burn Deaths from Pune Region
}

\author{
Jadhao Vijay $\mathbf{T}^{\mathbf{1}}$, Bandgar Abhijit $\mathbf{L}^{\mathbf{2}}$, Taware Ajay $\mathbf{A}^{\mathbf{1}}$, Tatiya Harish $\mathbf{S}^{\mathbf{2}}$, Vaidya Hemant $\mathbf{V}^{\mathbf{2}}$ \\ ${ }^{1}$ Associate Professor, ${ }^{2}$ Assistant Professor, Department of Forensic Medicine and Toxicology, \\ BJGMC, Pune, Maharashtra, India
}

\begin{abstract}
A burn is an injury which is caused by application of heat or chemical substances to the external or internal surfaces of the body, which causes destruction of the tissues. The magnitude of deaths due to burns is so large in our country that India is the only country in the world where fire is classified among the fifteen leading causes of death. The purpose of this study is to analyze profile of burn deaths in the Pune region of Maharashtra. In the present study among the 1710 burn deaths, females (70\%) are more commonly affected than males (30\%). Young adults (21-40 yrs) are commonly involved in fatal burns as this is most active group of population. In present study majority cases happened in summer season and were accidental in nature while suicidal deaths were present in significant number. Flame burns comprised of $80 \%$ of the cases followed by scald $13 \%$. In $78 \%$ of cases more than $50 \%$ of total body surface area was involved while complications like Septicemia (66\%) was commonest cause of death.
\end{abstract}

Key Words: Burn deaths, Pune region.

\section{Introduction}

A burn is an injury which is caused by application of heat or chemical substances to the external or internal surfaces of the body, which causes destruction of the tissues; thermal deaths are those which results from the effects of systemic and/or localized exposure to excessive heat and cold ${ }^{1}$. Thermal burns and related injuries are major cause of death and disability. Even in developed countries more than two million individuals annually are burned seriously and require medical treatment ${ }^{2}$. The magnitude of deaths due to burns is so large in our country that India is the only country in the world where fire is classified among the fifteen leading causes of death ${ }^{3}$. The prognosis of the burn injuries depends more upon the extent of body surface involved than upon degree/depth of the burns, which is traditionally determined by the rule of nines ${ }^{4}$. Burns are injuries produced by the application of dry heat such as flame, radiant heat or some heated solid substance to the surface of the body; while scald is moist heat injuries produced by 5 . Most of the deaths from burn injuries occur from shock within 24-48 hours; death due to toxaemia usually occurs within 4-5 days6. The purpose of this study is to study and analyze epidemiology with respect to age, sex, season and manner of death wise variation of burn deaths, also further study in detail for agent responsible for burns, percentage of total body surface area burned and cause of deaths in the Pune region of Maharashtra and to compare them with other studies.

\section{Material and Method}

In the present study, the medicolegal autopsies conducted between January 2015 to December 2019 at B.J. Government Medical College and Sassoon General Hospital, Pune, Maharashtra are analyzed retrospectively. Necessary information for the study is gathered from Police inquest report, hospital treatment records and discussion with the relatives, friends, and neighbors of the victims. The cases are studied to know the incidence of burn deaths with respect to age group, sex, and seasonal variation, further studied for manner of death, agent responsible for burns, percentage of total body surface area burned and cause of death wise variation of burn deaths.

\section{Observations and Discussion}

During the study period total 1710 medicolegal autopsies in burn deaths were conducted at B.J. 
Government Medical College and Sassoon General Hospital, Pune.

\section{Chart No 1: Sex Wise Distribution Of Burn Deaths}

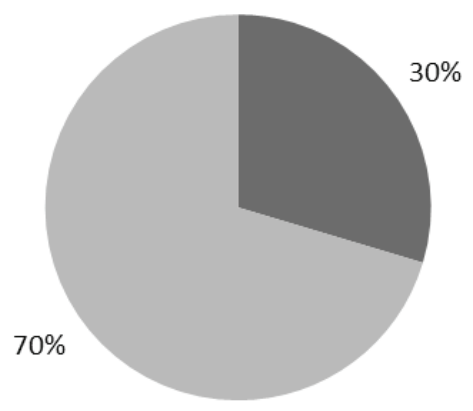

MALE $\quad$ FEMALE

In the present study, females (1185) i.e. 70\% were more commonly affected than males (525) i.e. $30 \%$ (Chart 1); similar findings were observed by Batra et al3, Ambade et al6 and Subrahmanyam M7; this can be explained by in India females being largely involved in domestic kitchen work that too at a very young age, with kitchen related activities place them at high risk of fatal burn accidents and also in our developing country child marriages and heinous dowry system being still prevalent likely leads to depression- suicide deaths and homicidal dowry deaths by burning incidents. The studies carried out in other developed countries showed male predominance like that in Japan 8, China9, Singapore 10 and South Korea 11 and which may be explained by the fact that because of rapid industrialization in these countries, male become more susceptible to fatal burns at work place.

Table 1: Age Wise Distribution of Burn Deaths

\begin{tabular}{|l|l|}
\hline Age group of deceased & Burn deaths \\
\hline 0 to 10 years & 148 \\
\hline 11 to 20 years & 150 \\
\hline 21 to 30 years & 475 \\
\hline 31 to 40 years & 292 \\
\hline 41 to 50 years & 234 \\
\hline 51 to 60 years & 70 \\
\hline 61 to 70 years & 186 \\
\hline More than 70 years & 155 \\
\hline Total deaths & 1710 \\
\hline
\end{tabular}


In the present study, highest number of deceased belonged to age group of 21 to 30 years, followed by 31 to 40 years (Table 1).These findings are consistent with studies conducted by Ambade et a16, Subrahmanyam M7 and Singh D et al12 this can be attributed to the fact that age group 21-40 yrs belongs to young adults,

which are commonly involved in fatal burn accidents in India as it is the most active group of population so more likely to be exposed to stress and family violence and burns may occur while working where awareness and adequate safety measures are not in place.

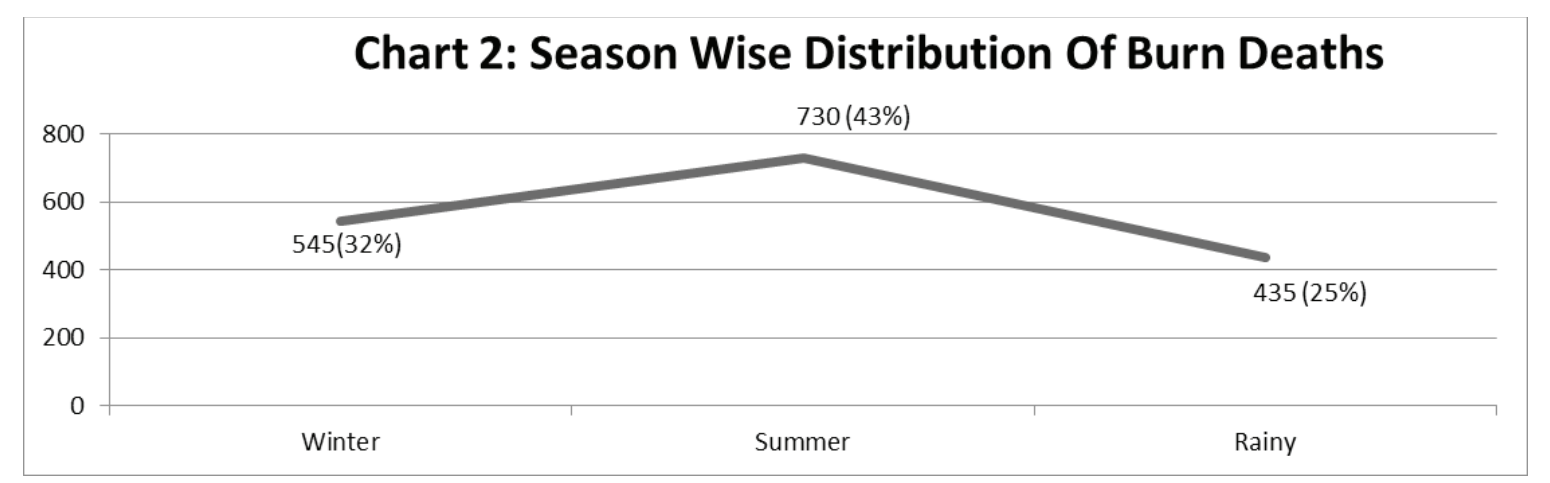

In the present study, when the burn deaths were analyzed in accordance with season, majority of cases 730 were in summer days followed by 545 in winter and then lowest 435 in rainy season (Chart 2).

Table 2: Manner Wise Distribution of Burn Deaths

\begin{tabular}{|l|l|l|l|l|}
\hline Manner & Accidental & Suicidal & Homicidal & Total Deaths \\
\hline Burn deaths & 1308 & 326 & 76 & 1710 \\
\hline
\end{tabular}

In present study out of 324 burn deaths, majority cases i.e. 1308 (79\%) were Accidental deaths while 326 cases were Suicidal and 76 cases were Homicidal in nature (Table 2). These findings are consistent with studies conducted by Batra et al4, Ambade et al5, Singh D et al6 and Subrahmanyam M7, this maybe because of frequent exposure to cooking, inadequate knowledge of handling high pressure stoves, too much demand of work leading to hurried job and accidents, the cooking activities involving fire associated with wearing of loose synthetic material leads to accidental burns. Suicidal and homicidal deaths were more common in married females. The reason for this may be old custom of dowry and marital disharmony which compel the married females either to commit suicide or they may be killed by their in-laws and husband.

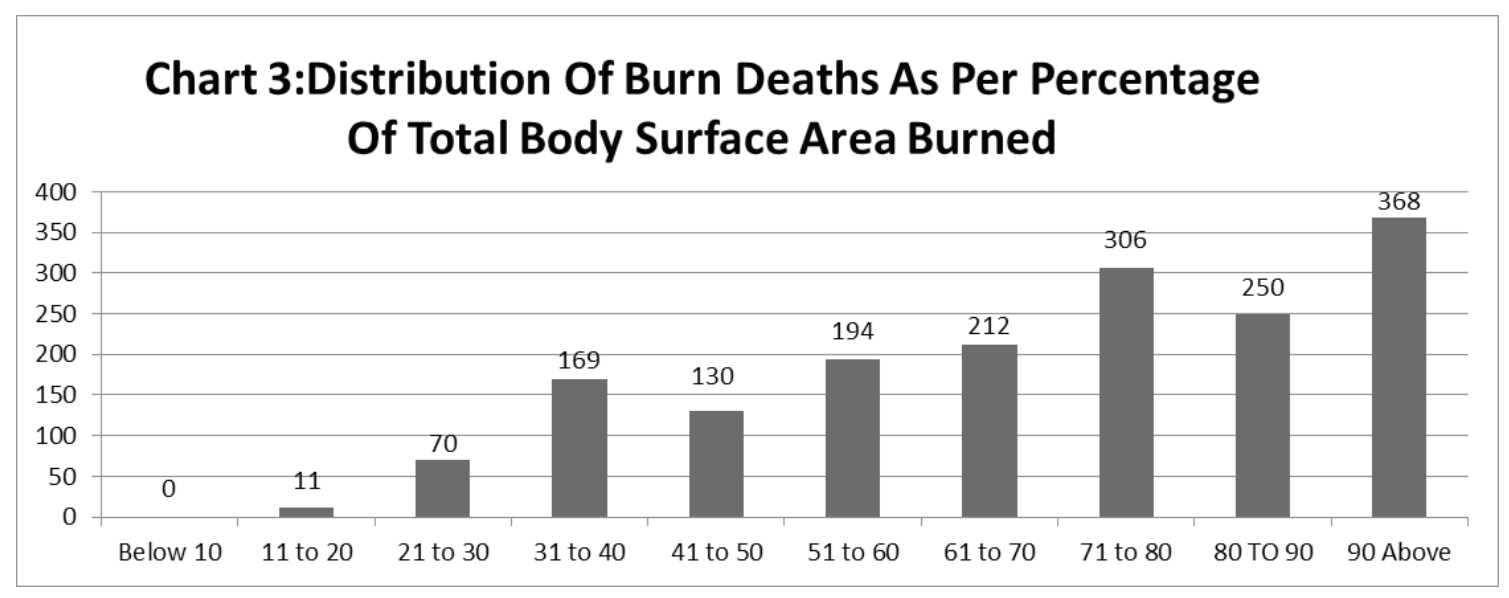


In the present study, it is observed that in 1330 cases (78\%) more than $50 \%$ of total body surface area was involved while in 380 cases (22\%) it was less than 50\% (Chart 3); this is consistent with studies conducted by Mangal HM et al13, Zanjad NP et al 14 and Chawla R et al15, which showed $77.34 \%, 84.4 \%$ and $86 \%$ cases respectively for surface burns more than $50 \%$ of total body area. It suggest that as the percentage of total body surface area burned involved goes on increasing the mortality rate in the patients increases.

Table 3: Responsible Agent Causing Burn wise distribution of Burn deaths

\begin{tabular}{|l|l|}
\hline Agent Responsible For Causing Burn & Number of Burn deaths \\
\hline Flame & $1368(80 \%)$ \\
\hline Scald & $216(13 \%)$ \\
\hline Electric & $114(6 \%)$ \\
\hline Chemical & $12(1 \%)$ \\
\hline Total deaths & 1710 \\
\hline
\end{tabular}

In the present study, flame burns comprised of 1368 (80\%) of the cases, followed by scald $216(13 \%)$ and electric burns $114(6 \%)$ while chemical burns were observed in 12 cases (Table 3). These findings are consistent with studies conducted by Batra et al4, Ambade et al5, Singh D et al6 and Subrahmanyam M7.

Table 4: Cause of death wise distribution of Burn deaths

\begin{tabular}{|l|l|}
\hline Cause of death & Number of Burn deaths \\
\hline Shock (Hypovolemic or Neurogenic) & $112(34 \%)$ \\
\hline Complications like Septicemia & $212(66 \%)$ \\
\hline Total deaths & 1710 \\
\hline
\end{tabular}

Immediate cause of death in burns is due to primary or neurogenic shock, secondary shock can cause death within 24 to 48 hours While after about 3-4 days toxaemia, septicaemia, acute renal failure, respiratory complications, thromboembolism causes death and after one week multiple factors comprise are sepsis, nutritional deficiencies, gangrene, etc. come in picture1. In present study, shock was cause of death in 112 numbers of cases while in majority of cases ccomplications like Septicemia were commonest cause of death. Similar findings noted by the studies conducted by Batra et al4, Ambade et al5, Singh D et al6 and Subrahmanyam M7, Bangal et al16 and Gupta el ${ }^{17}$.

\section{Summary and Conclusion}

The present study can be summarized and concluded as; burn deaths are presented in significant number in day to day medicolegal autopsies. Among burn deaths, females are more commonly affected than males. Young adults (21-40 yrs) are commonly involved in fatal burns as this is most active group of population. In present study majority cases are Accidental and Suicidal deaths are present in significant number. It was found that flame burns caused majority of the cases, followed by scald while as the percentage of total body surface area burned involved goes on increasing the mortality rate increases and complications like Septicemia were commonest cause of death. The results of this study suggest a strong relationship between particular age 
group and sex affected, manner of death, different causes of deaths; while focusing on these, attempts can be made to strategies therapeutic directions, medical and social interventions quite rightly to save life from burn deaths.

\section{Source of Funding: None}

Ethical Clearance: None.

\section{Conflict of Interest: Nil}

\section{References}

1. Reddy KSN. The essentials of Forensic Medicine \& Toxicology, 32th ed. Hyderabad: Suguna Devi K Medical Book Company; 2013: 302-14.

2. Baris Cakir, Berrak C.Yegen. Systemic Response to BurnInjury. Turk J. Med. Sci; 2004 (34): 215 216.

3. Batra. A. K. Burn Mortality; Recent Trends and Sociocultural determinants in rural India.Burns. 2003; (29): 270-275.

4. Krishan Vij. Textbook of Forensic Medicine \& Toxicology Principles and Practice, 6th ed. New Delhi: Reed Elsevier India Private Limited; 2014: 150-61.

5. Saukko P, Knight B. Knight's Forensic Pathology. 3rd ed. London: Arnold Publisher; 2004: 352-411.

6. Ambade VN, Godbole HV, Study of burn deaths in Nagpur, Central India, Burns; Nov 2006, 32(7): 902-8.

7. Subrahmanyam M., Epidemiology of burns in a district hospital in western India, Burns; Sep 1996, 22(6): 439-42.
8. Kobayashi K. et al, Epidemiological and outcome characteristics of major burns in Tokyo, Burns; Jan 2005, 31 Suppl 1: S3-S11.

9. Tang K. et al, Characteristics of burn patients at a major burn center in Shanghai, Burns; Dec 2006, 32(8): 1037-43.

10. Song C., Chua A., Epidemiology of burn injuries in Singapore from 1997 to 2003, Burns; Jan 2005, 31 Suppl 1:518-26.

11. Han TH et al, A retrospective analysis of 19,157 burns patients: 18-year experience from Hally Burn Center in Seoul, Korea, Burns; Jun 2005, 31(4): 465-70.

12. Singh D, Jash P., Tyagi S., Recent trends in burn mortality in northwest India and its preventive aspects, JIAFM; 1998, Vol 19. No.4: 79-88.

13. Mangal H. M., Pathak A, Rathod J. S; The Fire is Both A Blessing \& Scourge to the Mankind. JIAFM, 2007; 29(4): 75-77.

14. Zanjad NP, Godbole HV; Study of Fatal Burn Cases in Medico- Legal Autopsies. JIAFM, 2007; 29 (3): $42-49$.

15. Chawla R, Chanana A, Rai H, Aggrawal AD, Singh H, Sharma G; A two years burns fatality study. JIAFM 2010; 32(4): 291 - 297.

16. Bangal $\mathrm{R} S$ et al. Thermal injuries - a study of mortality pattern. Jr of Forensic Med and Toxicology. AIIMS 1995;12(2):1-4.

17. Gupta M, Gupta O, Yaduvanshi R, et al. Burn epidemiology: the pink city scene. Burns 1993;19;47-51. 